\title{
UTILIZATION OF HYDROGEN GENERATED BY USING ULTRASONIC TECHNIUQE AS A NEW SOURCE OF ENERGY FOR OPERATING A SMALL ENGINE
}

\author{
R. M. El-Oliemy ${ }^{1}$, A. M. H. El-Metwalli ${ }^{2}$, \\ M. R. Darwish ${ }^{2}$ and S. G. Hemeda ${ }^{3}$
}

\begin{abstract}
The main purpose of this work is to evaluate the possibilities of using the hydrogen as a clean fuel for the small horsepower engines. Due to the increasing spark ignition engine in the world, this caused deteriorating quality of air and due to the hydrogen combustion properties, which has a great effect on improving the performance of spark ignition engine. The engine was operated separately with each of Hydrogen or gasoline using a control valve, using the Ultrasonic-Hydrogen Electrolyzer System. In this article, all performance parameters of Ultrasonic-Hydrogen Electrolyzer System (UHES) were carried out such as the rate of hydrogen production and system efficiency under a different waveforms and wave frequency. The performance parameters of small horsepower gasoline single cylinder engine are carried such as the engine torque, engine revolution and power efficiency of an engine efficiency under the hydrogen gas-fuelled comparative with the pure gasoline-fuelled engine. The experimental results reveal that the triangular waveform has the maximum hydrogen production, UHES efficiency was $72 \%$ and the hydrogen can be increased power efficiency up to 9-10\% by using hydrogen without gasoline.
\end{abstract}

Keywords: Hydrogen, spark ignition combustion, waveform, ultrasonic, hydrogen production, and electrolyzer.

\section{INTRODUCTION}

Tncreasing emissions and predicting the future of the depletion of oil reserves around the world has strongly encouraged searching for alternative fuels (Haragopala et al., 1983). Hydrogen is one of alternative fuel. It has clean burning properties resulting in attention to using as fuel (Garni, 1995).

\footnotetext{
${ }^{1}$ Agricultural Engineer, Agric. Eng. Res. Inst., Agric. Res. Centre, Egypt.

${ }^{2}$ Assistant Prof., Agri. Eng. Department, Tanta University, Egypt.

${ }^{3}$ Researcher, Agric. Eng. Res. Inst., Agric. Res. Centre, Egypt.
} 
A significant reduction in power output was observed while using hydrogen in spark ignition (SI) engine. In addition pre-ignition, backfire and knocking problems were observed at high load. These problems have resulted in using hydrogen in SI engine within a limited operation range (Caton, 2001). Hydrogen can be used as a fuel in gasoline engines, which are the main engines now and in the future, and the hydrogen diffusion coefficient is 10 times as large as that of gasoline (Ji and Wang, 2009). Global attention to reducing fuel consumption and internal combustion engine emissions is an incentive for researchers to look for alternative solutions that do not require radical modification of engine design. These include the use of hydrogen as an alternative fuel to enhance engine efficiency and produce less pollution (Boretti, 2010). Most of the work focused on the use of pure hydrogen as an additive that combines the problem of hydrogen storage in mind. The use of hydrogen as an additive to gasoline has been in many studies (Ji et al., 2010). It was found that in the gasoline engine with higher ratios of hydrogen to gasoline ratios led to increased thermal efficiency brake in the production of higher energy than the engine and lower corresponding fuel consumption. Hydrogen has high free energy and very low density which requires storing a large amount of hydrogen and carrying it, which increases the total weight of the car (Fontana et al., 2002). Hydrogen can be used as a fuel in internal combustion engines either pure or mixed with other hydrocarbon fuels. Hydrogen can be used as a sole fuel in spark ignition (SI) engine, either by carburation or by direct injection (Das et al., 2002). Hydrogen combustion exhibits higher cooling loss to the combustion chamber wall than does hydrocarbon combustion because of its higher burning velocity and shorter quenching distance (Shudo and Suzuki, 2002). The first step in this study is to construct an ultrasonic hydrogen electrolyzer to generate the required flow for optimum performance and to be at an acceptable size and weight. The main objective of the present study is to use hydrogen in gasoline engines as clean fuel. The goal is to emphasize the great qualities they offer such as increased efficiency and peak pressure.

\section{MATERIALS AND METHODS}

The main experiments were carried out in the Power and Energy laboratory at Tractor and Farm Machinery Test and Research Station 
Alexandria Governorate. A model was manufactured and developed to determine the optimal configuration and the operating conditions for the gasoline engines by using an ultrasonic hydrogen electrolyzer.

\subsection{The ultrasonic hydrogen electrolyzer system (UHES)}

The UHES used in this study is shown in Figure (1). It consisted mainly of water electrolyzer unit, Ultrasonic Generator Unit and Power Amplifier unit (El-Oliemy et al., 2017).

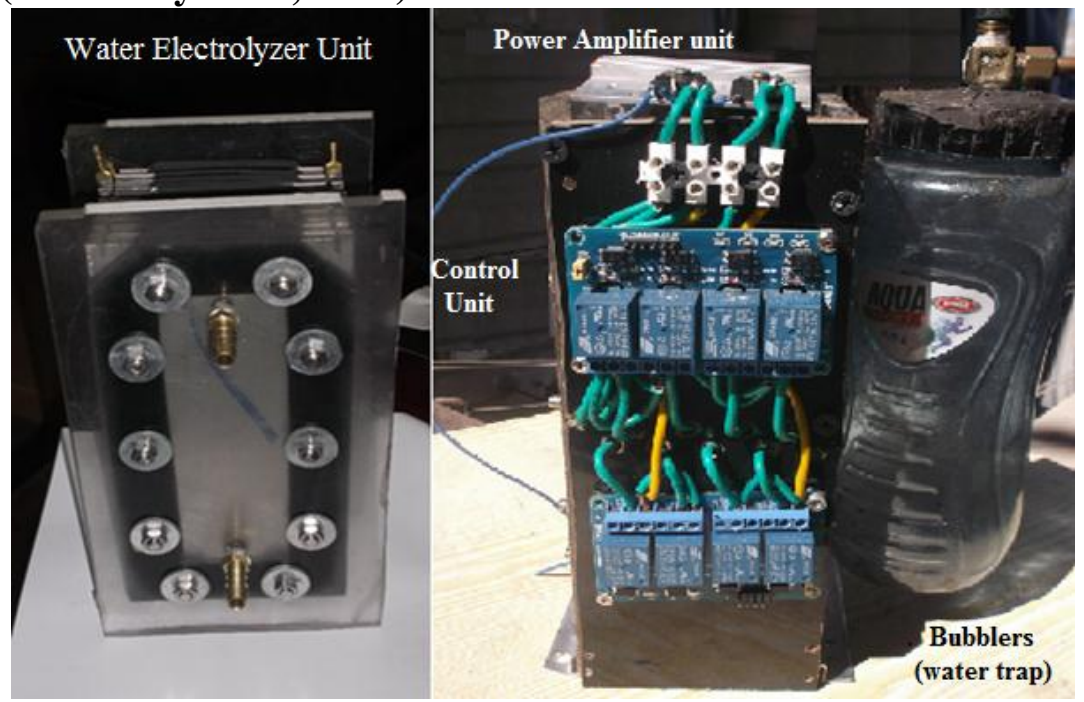

Figure (1). Ultrasonic-Hydrogen Electrolyzer System (UHES).

\subsubsection{Water electrolyzer unit}

Water electrolysis system made from stainless steel grade 310 plates with tabs on one end (anode and cathode electrodes) with a thickness of 0.9 $\mathrm{mm}$ and activity working surface area of $(5.5 \times 16 \mathrm{~cm}) 88 \mathrm{~cm}^{2}$. The electrodes separated by a rubber sheet $2 \mathrm{~mm}$ thick and assembled between two shelter plastic sheets $(160 \times 240 \times 10 \mathrm{~mm})$ by 10 stainless steel screw was recapping with polystyrene tube.

\subsubsection{Bubblers (water trap)}

Hydrogen was scrubbed by passing it through a water bubbler column. The scrubbing bubblers were made from a vertical plastic tube with end caps. A pair of the public nozzle was joined into holes drilled inside bottom caps of the acrylic plastic tube. The bubblers were filled with two-thirds full with water. The one-third empty of water was used as a product storage system. 


\subsubsection{Ultrasonic generator unit and power amplifier unit}

Figure (2) shows the schematic circuit diagram of the ultrasonic power amplifier with an output power of more than 1000 watt power amplifier circuit with high power uses 3 channel MOSFET's in the output stage alone gives about 400Watt power. Band switch (SW1) was used to select the input signal from signal generator to power amplifier (without ultrasonic, Square, Triangular and Sine) and (SW2) used to select the frequencies $(20,25$ and $30 \mathrm{kHz})$ while (RV4) to select the number of attached electrodes.

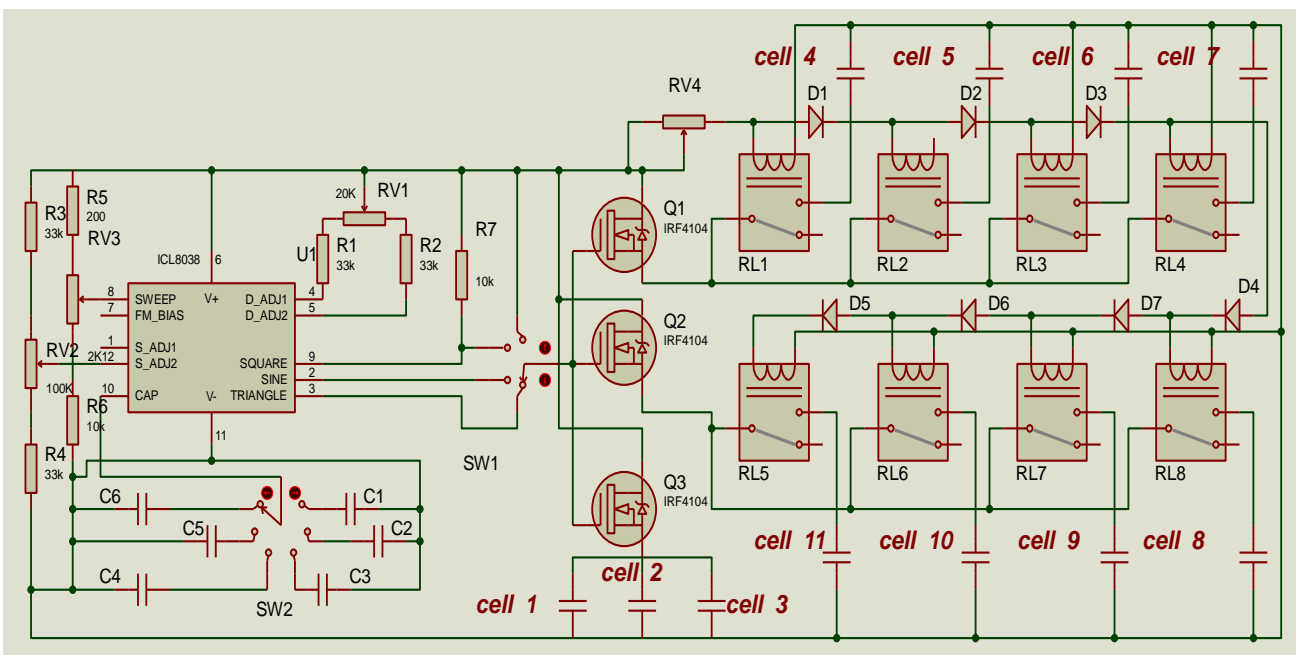

Figure (2). The schematic diagram of ultrasonic power amplifier.

\subsection{Gasoline engine}

The engine used in this work was a spark ignition engine manufactured by Dayun Company. Brief specifications of the engine are shown in Table (1).

Table (1). Engine specifications.

\begin{tabular}{|l|l|}
\hline \multicolumn{1}{|c|}{ Item } & \multicolumn{1}{c|}{ Value } \\
\hline Engine weight (Dry) & $21.5 \mathrm{~kg}$ \\
\hline Engine type & Air Cooled 4-stroke \\
\hline Cylinder arrangement & Single cylinder Horizontally mounted \\
\hline Displacement & $149.74 \mathrm{~cm}^{3}$ \\
\hline Bore $\times$ stroke & $62.0 \times 49.6 \mathrm{~mm}$ \\
\hline Compression ratio & $12.1: 1$ \\
\hline
\end{tabular}




\subsection{Measuring system}

Figure (3) shows the measuring system which consists mainly of :

- Strain gauge transducer.

- Data Logger.

- Brake system.

- RPM Sensor.

- Slip Ring

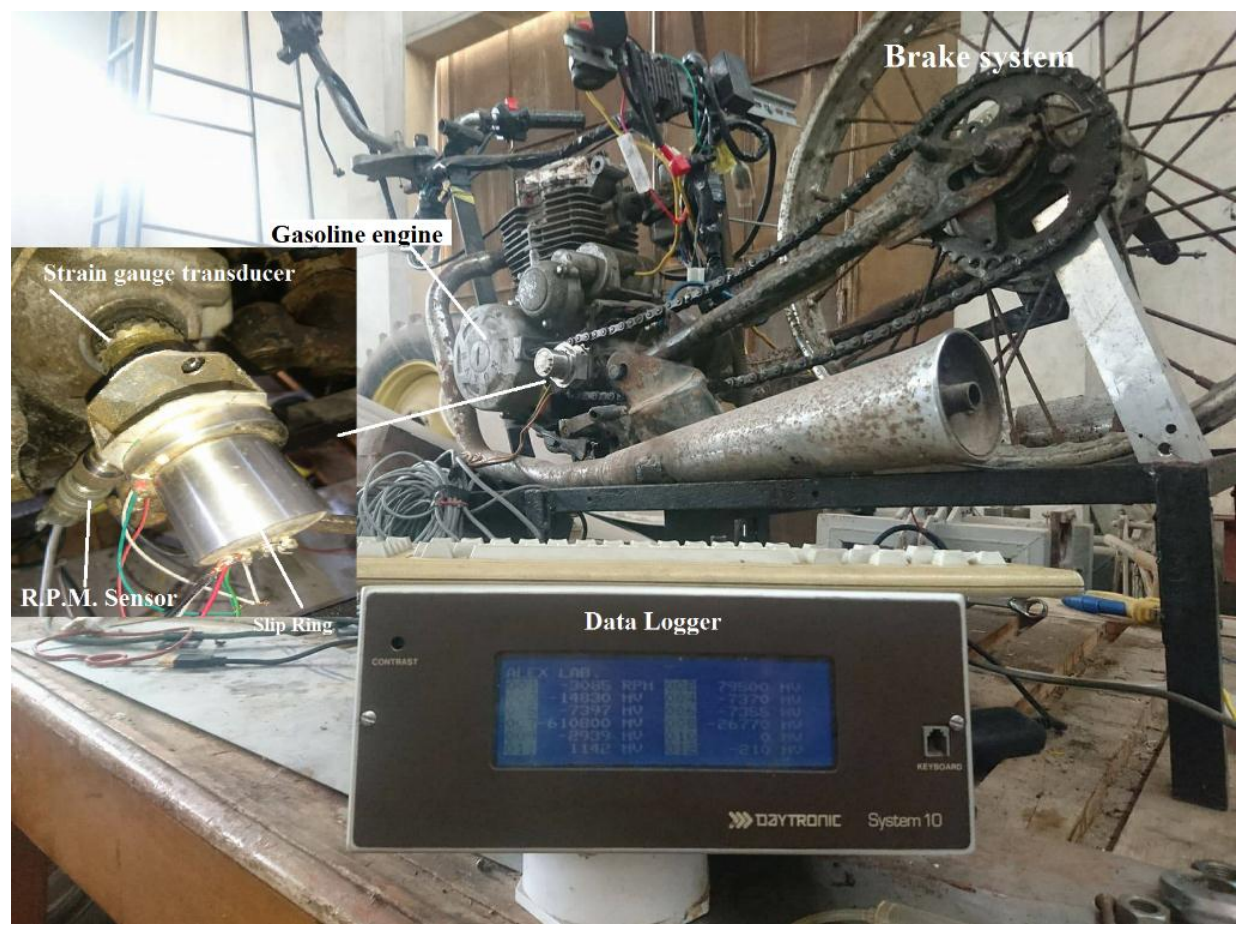

Figure (3). The measuring system.

\subsection{Experimental setup and procedure}

The UHES and the brake system with data logger is shown in Figure (3).

- The UHES is attached to the engine.

- The hydrogen output is connected to the carburetor through the rubber pipes.

- The UHES anode is connected to the starter of the engine through the electric wire and its cathode is connected to earth.

\subsection{Performance evaluation of system}

\subsubsection{Hydrogen production rate}

The hydrogen production rate $\left(\mathrm{fH}_{2}\right)$ was volumetrically measured by cumulated hydrogen per replication under laboratory conditions using the water displacement metering system. The hydrogen production was 
recalculated at the standard conditions $\left(0{ }^{\circ} \mathrm{C}\right.$ and 1 bar $)$ to adjust the volume of hydrogen production. Hydrogen production rate $\left(\mathrm{f}_{2}\right)$ for the Ultrasonic-Hydrogen Electrolyzer System was calculated using Eq. 1 (Gosch et al., 1983):

$$
f_{H 2}\left(\frac{N m^{3}}{h}\right)=\frac{V t r}{t}
$$

Where $\mathrm{Vtr}$ is total hydrogen production volume at standard conditions of $0^{\circ} \mathrm{C}, 101.325 \mathrm{kPa}, \mathrm{Nm}^{3}$ and $(\mathrm{t})$ is operational time, $\mathrm{h}$.

\subsubsection{Electrolyzer efficiency}

Electrolyzer efficiency $\left(\eta_{E}\right)$ represents the ratio between the energy contained in the produced hydrogen relative to Higher Heating Value (HHV) of hydrogen $\left(3.54 \mathrm{kWh} / \mathrm{Nm}^{3}\right)$ and the energy consumption $\mathrm{CE}$ in $\mathrm{kWh} / \mathrm{Nm}^{3}$ (Alfredo et al., 2012).

$\eta_{E}=$

$\frac{H H V \text { of } H_{2}}{C_{E}} \times 100$

\subsubsection{Engine power efficiency}

Power efficiency (PE,\%) was calculated using the following formula:

$\mathrm{PE}=\frac{\text { Hydrogen Engine Power }- \text { Gasoline Engine Power }}{\text { Gasoline Engine Power }} \times 100$

\section{RESULTS AND DISCUSSION:}

\subsection{Hydrogen production rate}

The UHES hydrogen production rate is significantly affected by many operational parameters such as waveforms and the signal frequencies. Figure (4) shows the UHES hydrogen production rate under all treatments. The ultrasonic wave reduces the polarization impedances. Notably, ultrasonic power correlates positively with impedance reduction. In addition, ultrasound accelerates the deviation of bubbles from the electrode surface and instantly reduces the occurrence of phenomena related to polarization impedance. These results were in agreement with that obtained by (Ming and Hourng, 2014; Zadeh, 2014).

\subsection{Electrolyzer efficiency}

The effect of the waveforms and signal frequencies on UHES efficiency is shown in Figure (5). It is evident from Figure (5) that the electrolyze efficiency was found to increase with different values of signal frequency 
and waveform. These results were in agreement with that obtained by (Zadeh, 2014).

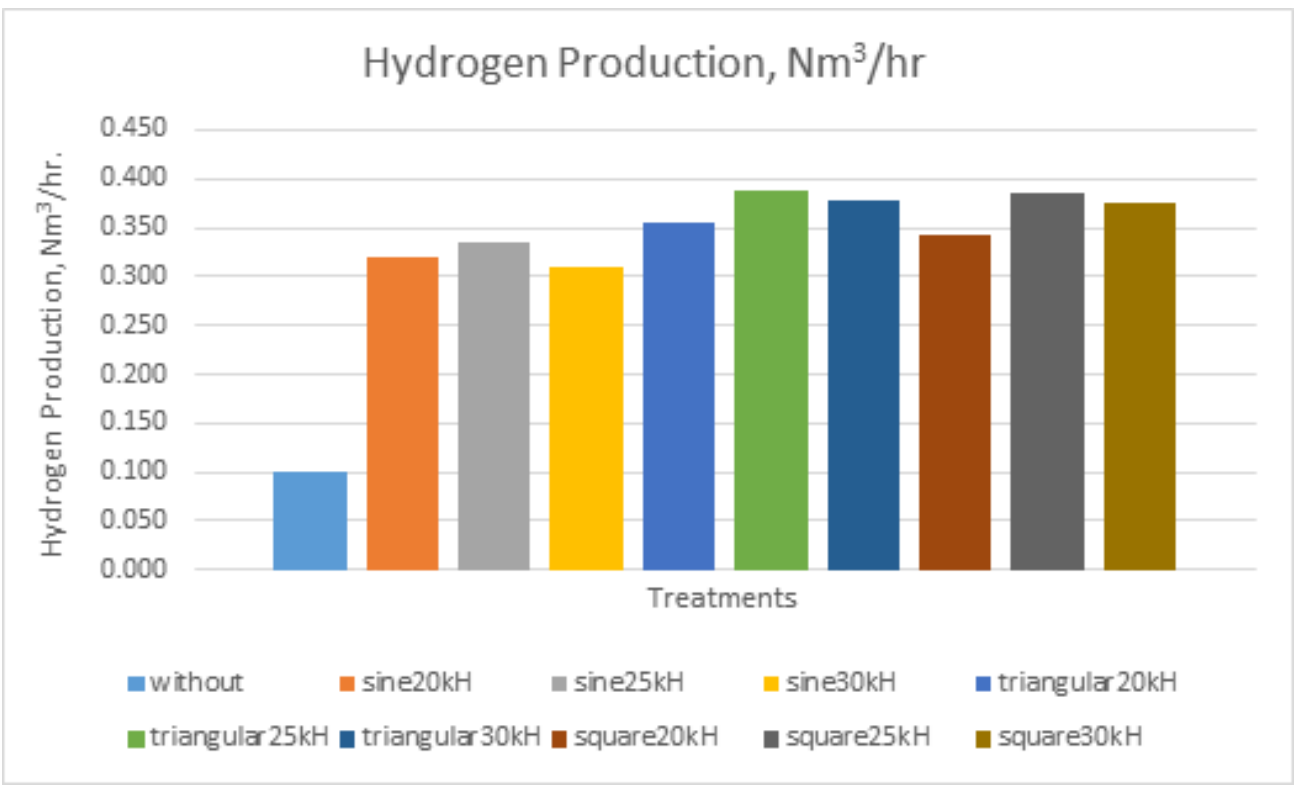

Figure (4). Hydrogen production under different waveforms and signal frequencies.

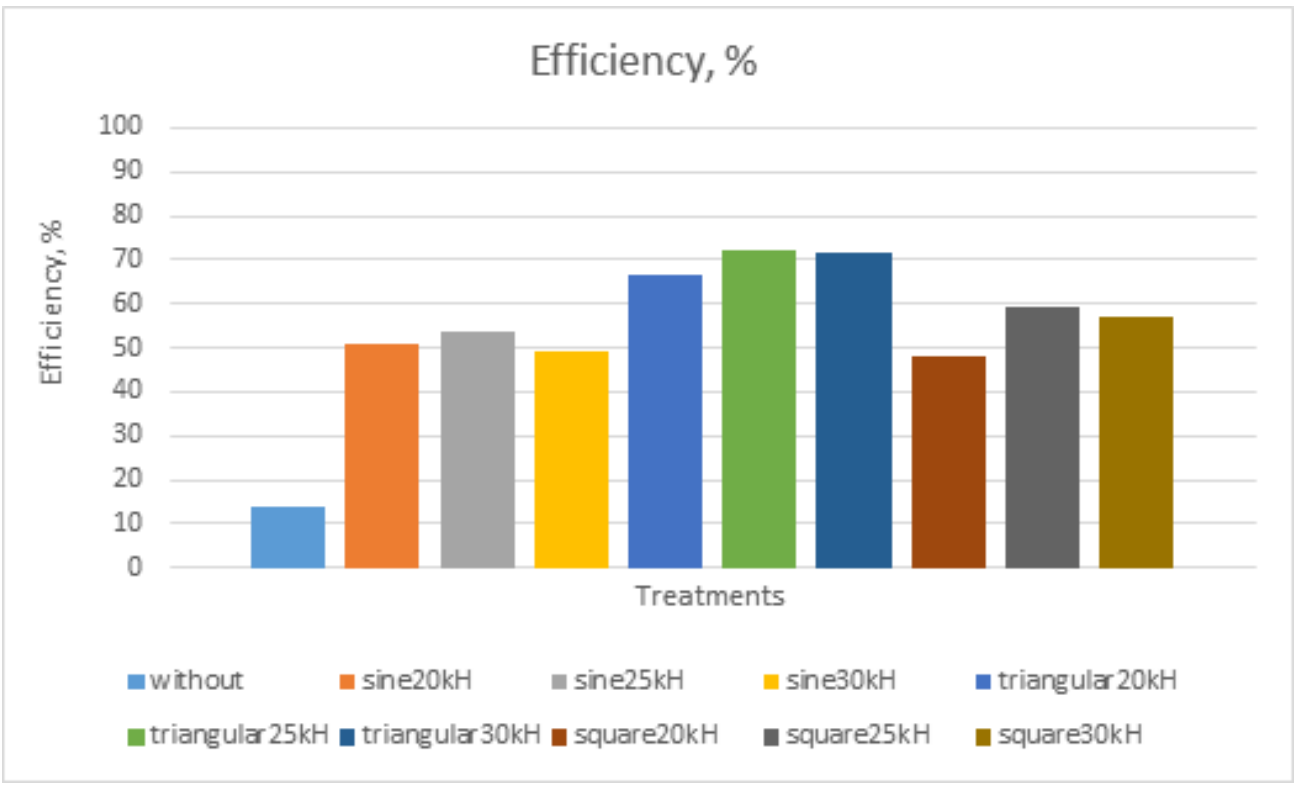

Figure (5). UHES efficiency under different waveforms and signal frequencies. 


\subsection{Performance test result}

Performance test result of the engine at 3rd Gear test is carried out in Table (2). The data from Table (2) experimentally found out that the power efficiency of an engine can be rapidly increased up to $9-10 \%$ by using hydrogen without gasoline.

Table (2). Performance test result of the engine:

\begin{tabular}{|c|c|c|c|c|}
\hline \multicolumn{2}{|c|}{ Gasoline } & \multicolumn{2}{c|}{ Hydrogen } & \multirow{2}{*}{ Efficiency } \\
\cline { 1 - 3 } Torque & $\begin{array}{c}\text { Engine } \\
\text { Revolution }\end{array}$ & Torque & Engine Revolution & \\
\hline (N.m) & (RPM) & $($ N.m) & (RPM) & $\%$ \\
\hline 3 & 429 & 3.1 & 450 & 8.39 \\
\hline 6.1 & 385 & 6.2 & 417 & 10.09 \\
\hline 9.1 & 336 & 9.1 & 370 & 10.12 \\
\hline
\end{tabular}

\section{CONCLUSIONS}

In this work, an ultrasonic water electrolyzer was designed and constructed to produce hydrogen gas to be used as a clean fuel in gasoline engines from the experimental results, it can be seen that the triangular waveform has the maximum hydrogen production followed by sine waveform, UHES efficiency was $72 \%$ and the hydrogen can be increased power efficiency up to $9-10 \%$ by using hydrogen without gasoline.

\section{REFERENCES}

Alfredo, U., M. Luis, A. Gand and Sanchis (2012). Hydrogen production from water electrolysis: Current Status and Future Trends. Proceedings of the IEEE,100(2):410 - 426.

Boretti, A. (2010). Comparison of fuel economies of high-efficiency diesel and hydrogen engines powering a compact car with a flywheel-based kinetic energy recovery systems. Int. J. Hydrogen Energy 35: 8417-8424.

Caton, J. A. (2001). An investigation of cause of backfire and its control due to creviced volumes in hydrogen-fueled engine. Trans ASME,23:204-210. 
Das, L.M. (2002). Near-term introduction of hydrogen engines for automotive and agricultural application. International Journal of Hydrogen Energy, 27(5): 479-487.

El-Oliemy, R. M., A. M. H. El-Metwally, M. R. Darwish and S. G. Hemeda (2017). Design and development of an ultrasonic electrolyzer system for hydrogen production. Sci. Int. (Lahore), 29(5):4501-4506.

Fontana, A., E. Galloni, E. Jannelli and M. Minutillo (2002). Performance and fuel consumption estimation of a hydrogen enriched gasoline engine at part-load operation. SAE Paper No. 2002-01-2196.

Garni, M. (1995). A simple and reliable approach for the direct injection of hydrogen in internal combustion engines at low and medium pressures. Int J Hydrogen energy,20:723-726.

Gosch, A., M. Hildegrate, W. Ursula and J. Walter (1983). The anaerobic treatment of poultry manure. Animal Res. And Dev., 17: 62-73.

Haragopala, R. B., K. N. Shrivastava and H. N. Bhakta (1983). Hydrogen for dual fuel engine operation. Int $\mathbf{J}$ Hydrogen energy, $8: 381-384$.

Ji, C. and S. Wang (2009). Effect of hydrogen addition on the idle performance of a spark ignited gasoline engine at stoichiometric condition. Int. J. Hydrogen Energy, 34(8):3546-3556.

Ji, C., S. Wang and B. Zhang, (2010). Combustion and emissions characteristics of a hybrid hydrogen-gasoline engine under various loads and lean conditions. Int. J. Hydrogen Energy, 35(11):57145722 .

Ming, Y. L. and L. W. Hourng (2014). Ultrasonic wave field effects on hydrogen production by water electrolysis. Journal of the Chinese Institute of Engineers, 37(8):1080-1089.

Shudo, T. and H. R. Suzuki (2002). Applicability of heat transfer equations to Hydrogen combustion. JSAE Review,23:303-308. 
Zadeh, S. H. (2014). Hydrogen production via ultrasound-aided alkaline water electrolysis. Journal of Automation and Control Engineering, 2(1):103-109.

\section{الملخص العربي}

استغلال الهيلروجين المولد باستخدام الموجات فوق الصوتية كمصدر جديد

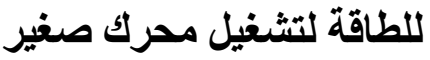

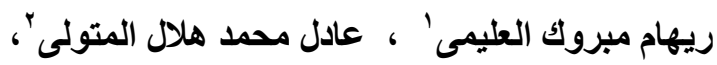

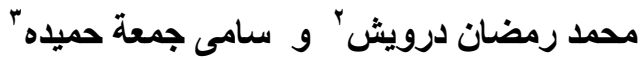

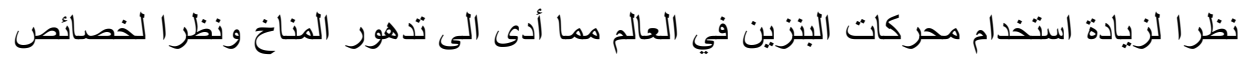

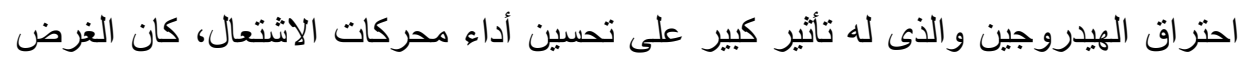

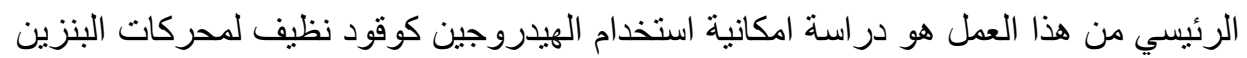

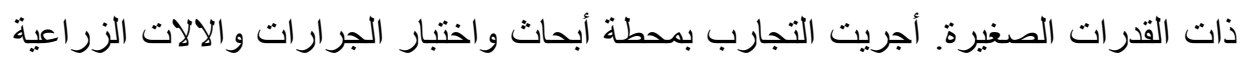

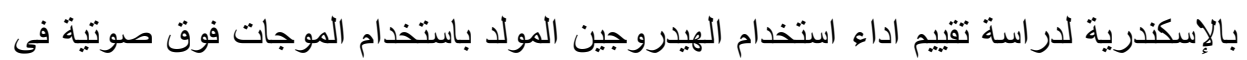
محركات البنزين الصغيرة وتم تنفيذ التجارب آخذين في الاعنبار أداء النظام الكهربائي الكئي

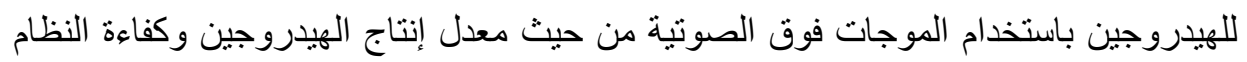

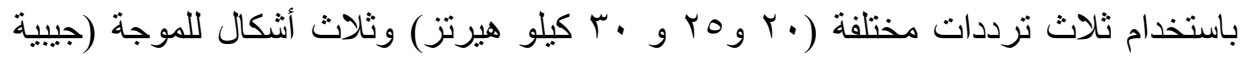

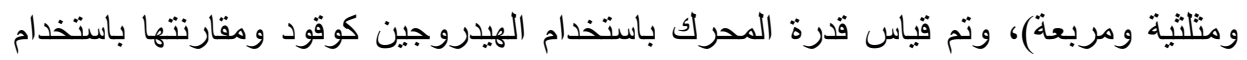

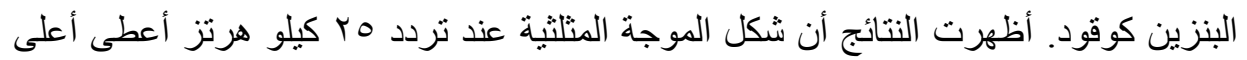

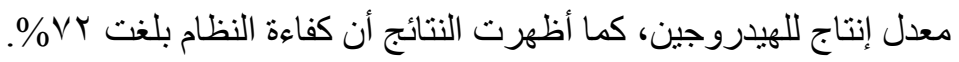

' مهندس زراعي، معهد بحوث الهندسة الزراعية، مركز البحوث الزراعية، مصر .

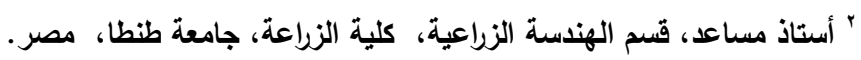

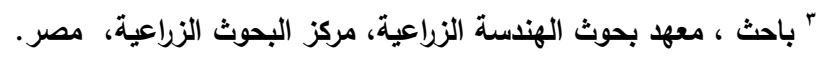

